\title{
Prospects for the development of stay in plase formwork for low-rise buildings in cramped conditions
}

\author{
Pavel Gaidukov*and Evgeniy Pugach \\ Moscow State University of Civil Engineering, 129337, Moscow, Russia
}

\begin{abstract}
The article considers existing and promising systems for the construction of slabs in low-rise buildings using stay in place (SIP) formwork. The main conditions for using these formwork systems are described and the disadvantages of existing structures are highlighted. Using the example of previously patented inventions, various trends in the development of formwork systems are revealed. The article deals with precast concrete structures of fixed formwork, modular structures of fixed formwork, various types of connections. Variants of fixed formwork with different types of installation and delivery of concrete mix, made of different materials and shapes are considered. The main individual features of each type of invention are highlighted, on the basis of which assumptions are made for the development of these systems. Based on the results of the analysis, the article offers technical requirements and a brief description of a promising formwork system for the construction of floors of low-rise buildings in cramped conditions.
\end{abstract}

\section{Introduction}

The increased growth rate of low-rise construction and the constantly deteriorating state of the low-rise building stock create a need to develop new solutions for construction and reconstruction. Also, prefabricated low-rise buildings are relevant for regions that are remote from industrial centers or located in hard-to-reach areas. Prefabricated buildings can also be used when urgent construction of buildings is required in areas of emergencies and natural disasters. One of the key elements of buildings and structures are overlaps. The construction of wall structures made of individual materials (such as concrete blocks or bricks) or sandwich panels allows you to build them without the use of crane equipment and other means of mechanization. Crane equipment is used not only for the supply of concrete mix to the place of production of concrete, but also for the supply and subsequent installation of

*Corresponding author: aljurgaitis@gmail.com 
elements of shuttering systems such as telescopic support posts, longitudinal and transverse beams, plywood shuttering boards. Construction of floors is currently impossible without the use of crane equipment or means of feeding concrete mix. This has a negative impact on the production time and material costs of equipment.

It should be noted that most of the applied reinforced concrete, steel and wooden floors need additional insulation, anti-corrosion treatment or waterproofing. The solution to this problem is the use of prefabricated floor structures made of piece materials that allow you to build floors without crane equipment. This type of overlap can also have other useful features. Depending on the material, method of manufacture and type of connection, these structures may have increased thermal and noise insulation properties.

\section{Features of construction low-rise buildings slabs in cramped conditions}

Today, there are two main directions for the manufacture of floors of low-rise buildings and structures. The first of them is the device of monolithic floors made of heavy concrete in a beam or similar panel formwork. The second method is the device of overlappings made of reinforced concrete slabs of factory manufacture. When using a standard beam formwork technology to follow the construction of the ceiling the following: in the beginning exhibited the strut Assembly with jacks, they installed the main and distributing beams, the deck is formed from sheets of formwork plywood, mounted reinforcement cage, made supply and placing of concrete. After a set of concrete Stripping strength, the formwork of the slab to be dismantled and relocated to the next site. Figure 1 shows a diagram of a beam-panel formwork. As can be seen from the diagram, the following requirements must be met for the overlap device. Under the constructed floor must be arranged base (interstory floor, Foundation plate), able to withstand the load from the new structure at the stage of the device formwork, concreting and holding the structure. There must be a way to supply large-sized devices and materials such as boards and formwork beams, reinforcement of floor grids. Special attention should be paid to the method of feeding concrete mix: for the use of buckets, it is necessary to have no structures above the work horizon, which is not always possible in the conditions of reconstruction; the use of a concrete pump in cramped conditions during the reconstruction or construction of low-rise buildings due to the small volume of concrete work is not always economically feasible. Also, due to the small volume of concrete mix in the case and the desire to reduce material costs, incomplete or completely non-innovative sets of formwork systems are used, which lead to a decrease in the quality of finished structures and provoke emergencies both at the construction stage and at the stage of further operation. 


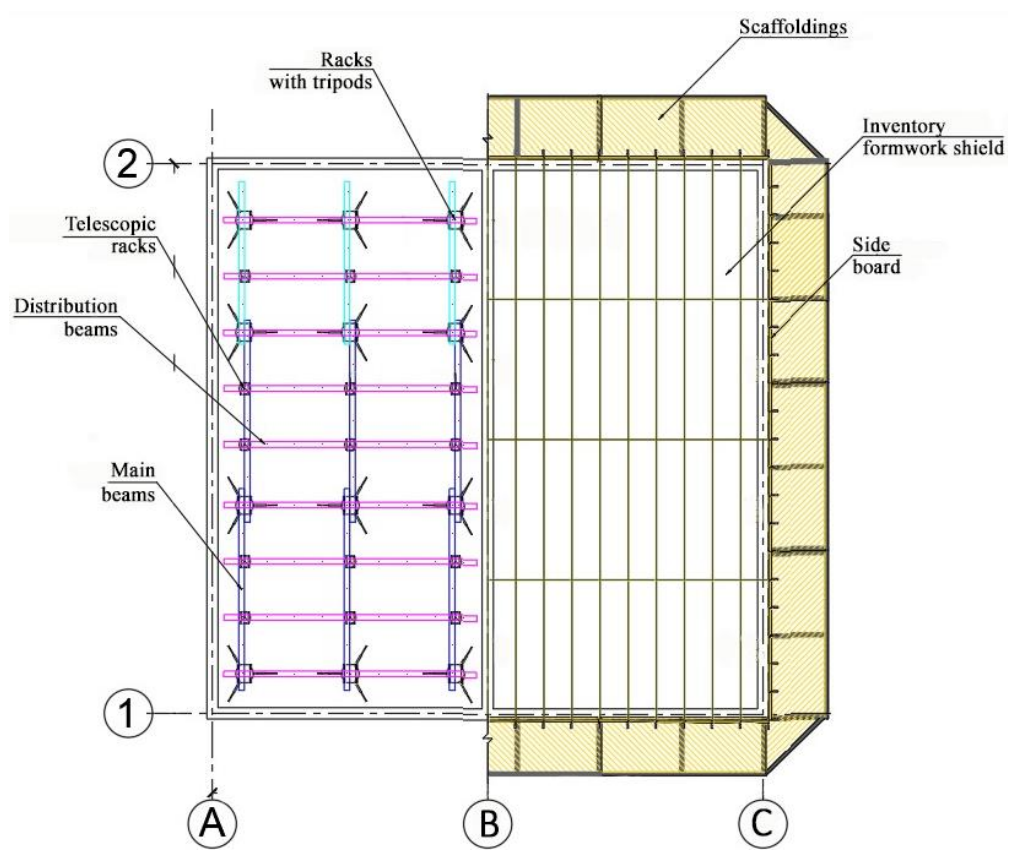

Fig.1. Scheme of the block-panel formwork of the floor.

The second method is the use of ready-made reinforced concrete floor slabs for the device of a prefabricated floor. With the apparent cheapness of a single reinforced concrete product, the main costs for the device of such an overlap will take material and transport support. In addition, the use of precast concrete in the form of ready-made factory floor slabs introduces the following features into the construction project of the building. There is no variability in the choice of space-planning solutions of the building, as all dimensions become dependent on the size of the floor slabs. The exact same due to the large size and mass transportation of slabs can be made only special side semi-trailers, which makes them difficult delivery in dense urban areas and difficult to access for similar vehicles places. Installation of factory floor slabs is only possible with crane equipment with sufficient lifting capacity and boom reach. The need not only to unload the plates from vehicles, but also to raise them to the design mark requires a wheeled crane with a high load capacity at the maximum boom reach or the use of small-prefabricated tower cranes. The features described above do not allow us to call prefabricated floors made of reinforced concrete slabs the optimal way to manufacture floors.

The use of SIP formwork allows you to remove from the technological process a number of operations for dismantling large-sized elements such as formwork panels. Currently existing technical solutions in the form of, for example, fixed beam formwork floors allow you to build floors without the use of lifting equipment. Beam fixed formwork combines elements of a prefabricated monolithic floor and fixed formwork, this system has the smallest of the considered mass and size indicators of individual elements. In General, fixed beam formwork is a prefabricated structure made of steel (less often steel-concrete) beams and voids made of various materials such as light concrete, aerated concrete, and ceramics. However, the large size of the beams, the need to fill the concrete mix and the need to install support posts does not give a decisive advantage over standard formwork. The use of non-removable floor formwork reduces the labor intensity of the construction process by an average of $31 \%$ compared to the use of classical beam-panel formwork, in the case of non-removable floor beam formwork by $44 \%$ [1]. For floors arranged in cramped conditions 
with the use of fixed beam formwork, the labor cost values did not exceed the indicators for the construction of a structure using beam-panel formwork under normal conditions. With lower labor costs, fixed formwork systems prove their relevance in modern construction.

\section{Promising directions for the development of SIP floor formwork}

Work on improving and developing new overlap systems is being carried out in several directions. The product patent developed by ZHEJIANG GONGSHANG CHU [2] (fig. 2) is an overlap assembled from a hollow block. The block is a hollow rectangle whose front and back sides are connected by concave surfaces or connected on a spike, and the right and left ends of which are mounted on a beam, and the upper surface and lower surface are grooved. The utility model combines rigidly locked hollow blocks and beams that form a rigid overlap.

Overlap has the advantage of light weight, high strength, sound insulation, thermal insulation, impermeability, impact resistance.

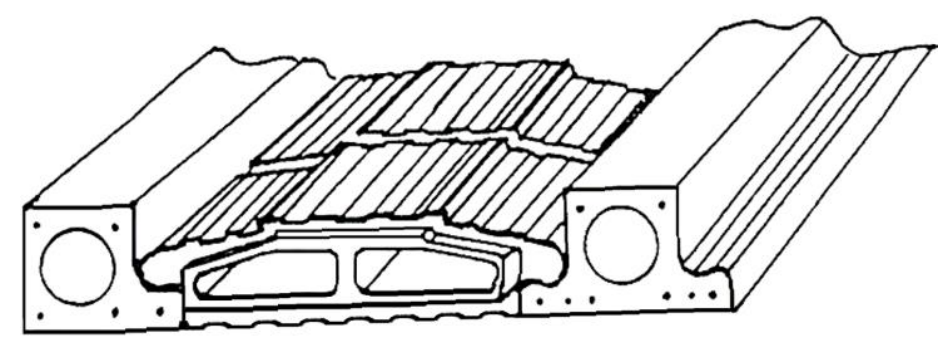

Fig. 2. Hollow block slab.

The second type of development of prefabricated slabs is a composite structure of non-removable formwork. The basic principle is to create a canvas on the principle of a puzzle from individual light elements made by pressing from various materials. The product patent developed by JEAN LEVAVASSEUR [3] (fig. 3) is a block molded from recycled plastic material with a mineral or organic filler with an open bottom surface, a closed top surface and a peripheral wall. It has internal partitions lying perpendicular to the closed upper face. Internal partitions intersect with each other, and some of them have recesses for filling with rolling stock. The blocks are connected to each other on the principle of a puzzle forming a hard surface ready for laying concrete mix.

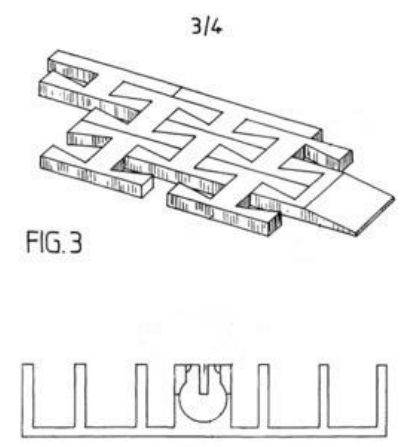

FIG.4

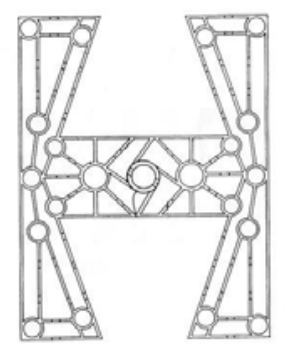

FIG 5

Fig. 3. Puzzle from. 
The following invention can also be attributed to this group of fixed formwork. Panel stay in place formwork proposed By Trushchev A. G., Simkin S. V. and Ivanov G. P. (fig. 4) is a reinforced concrete formwork plates with connecting elements in the form of symmetrically expanding bevels for mutual coupling of plates with each other [4]. The proposed formwork system allows you to perceive the operating load from the floor slab and is able to perceive the tensile forces in both one and two directions, which allows you to include it in the work of the floor slab as a whole.
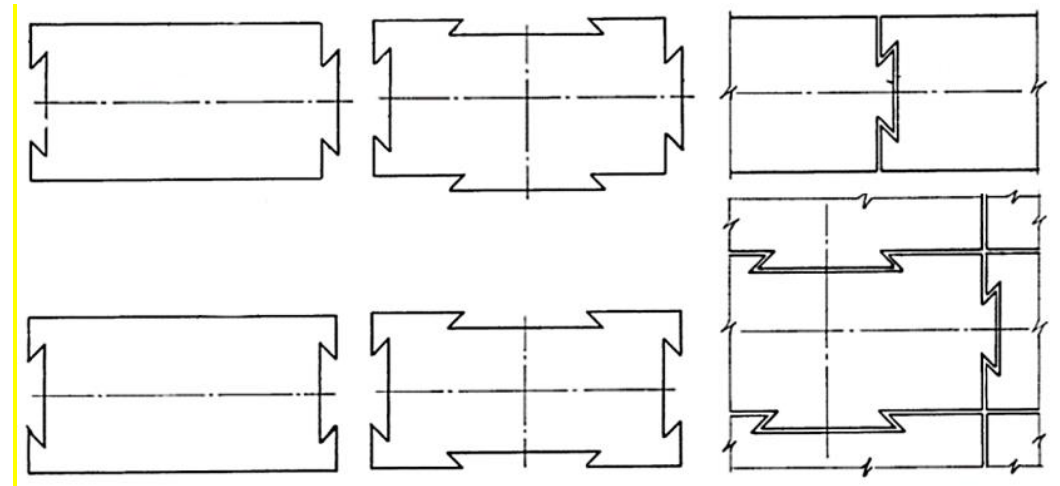

Fig. 4. Panel stay in place formwork.

Using the example of the two previous inventions, it is possible to identify trends in the further development of the technology of prefabricated floors made of piece elements. The new system should combine the properties of a fixed formwork with engagement and a hollow block. As an example of such a system, we can refer to inventions in related fields. The invention of KIM, KYU HAN [5] (fig. 5) refers to a block for blocking coastal flow that prevents coastal erosion by placing between coastal structures. The block has a pair of wall sections perpendicular to the sea floor, and is generally fully formed, since the cover section and the floor section are respectively equipped with upper and lower sections between the wall sections. The bottom-curved part has an ascending part on the intake side and a descending part of the slab on the exhaust side.
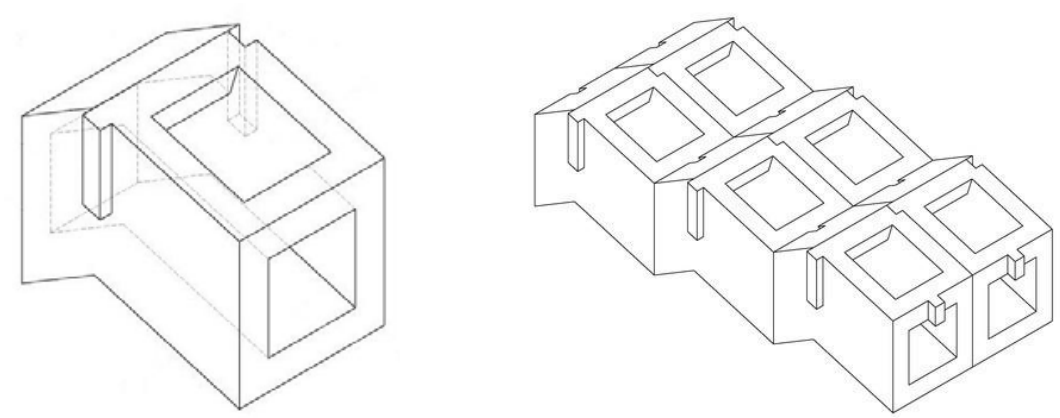

Fig. 5. Block for blocking coastal flow.

Hollow blocks of this design have a spike on one wall and a counter groove on the opposite wall. This connection creates a rigid fixation of the structure in the horizontal plane. A similar mechanism can be used for permanent formwork. Hollow blocks that make up the floor structure and have a load-bearing capacity at the installation stage due to mechanical engagement. The hollow block of the formwork allows you to reduce the total weight of a single element. After installation of the structure, it is possible to fill the block cavity with various thermal and sound insulation materials, which will increase the insulation 
performance of the floor as a whole. Both of the above inventions are distinguished by the method of connection. In both designs, the connection is due to the details of the forms themselves made of the same material as the product itself. These connections also perform the role of a controller during installation, which allows you to perform these structures for workers of average qualification.

In addition to the above-mentioned directions of development of non-removable floor formwork, an approach aimed at combining the system of non-removable formwork with forms of blockouts in monolithic floors is singled out separately. Blockouts are installed in a monolithic reinforced concrete floor slab in order to reduce the volume of poured concrete mixture in the least stressed sections of the structure. Reducing the volume of reinforced concrete in the floor slab leads not only to material savings, but also to a disproportionate reduction in labor costs and machine time for the production of concrete works. Anpilov Sergey [6] expressed the idea to combine the formwork Board of a fixed formwork with the hollow-forming floor slab. His patented formwork element (fig. 6) including the outer surface and the working surface, made in the profile view, the outer working surface of which has qualitatively similar, the profile made in cross-section in the form of an open loop trapezoid with the top small base-shelf and a lower, larger base made with flanging, characterized in that it is modular, in the plane of the base shelves are made of the protrusions, the width of the protrusion is the smallest width of the strake, and the height of the protrusion is not less than the value of the protective layer of concrete reinforcement mesh, moreover, on the base-shelf and side surfaces of the open trapezoid profile of the universal modular formwork element, transverse stiffeners are made in the form of three-dimensional geometric shapes.

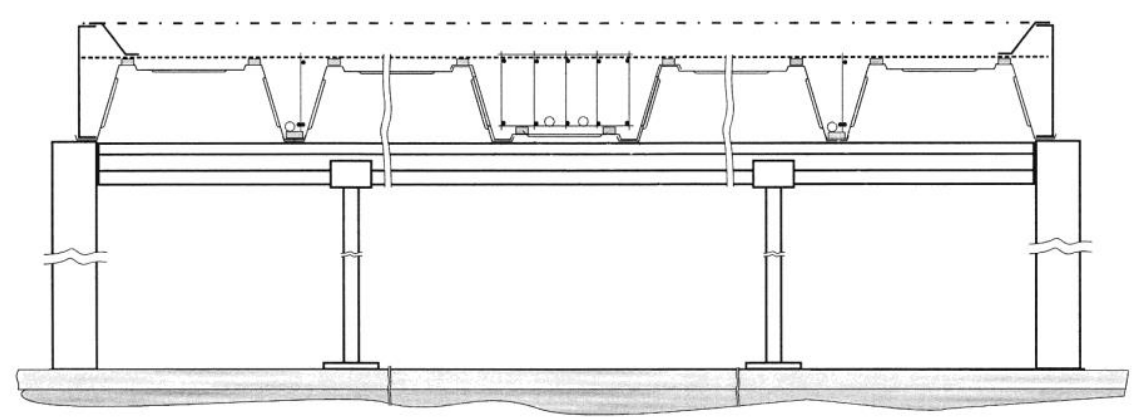

Fig. 6. SIP formwork with blockout.

After mounting the forming parts on the supporting pillars in the space formed by the mating parts, the reinforcement frame of integrated beams made of rod reinforcement of various diameters is laid, after which the structure is filled with a concrete mixture. The concrete mix is fed by a concrete pump or hopper. After gaining strength, the support struts are removed.

Based on the above developments, we can assume the further development of non-removable formwork systems for the construction of floors in non-removable formwork. Together, the inventions presented above have the following novelty: the entire structure is made of separate modules, the material is concrete or plastic, the system is fixed mechanically due to the details of the structure, the fixing system consists in the use of spikes and grooves, after installation of the structure, concreting is carried out. All the structures presented above to some extent meet the requirements for the construction of floor structures of low-rise buildings in cramped conditions [7]. However, each of them requires additional 
work such as the installation of support racks, the use of small mechanization tools and the supply of concrete mix by concrete pumps or concrete bunkers. Based on the above advantages of each development, this article offers a technical description of a promising formwork system.

Having analyzed all the above-mentioned inventions, it is possible to determine the main tasks set for a promising shuttering system. These are the expansion of the field of application of fixed formwork in low-rise housing construction, the ability to produce floors of buildings and structures without the use of crane equipment and mechanized means of feeding concrete mix, the ease of installation of formwork elements manually, ensuring the quality of finished ceiling surfaces formed by the formwork.

A promising formwork system for the construction of floors of low-rise buildings should have the following key characteristics. The construction of the ceiling structure should be possible without the use of crane equipment. The ability to install the structure manually allows you to expand the scope of its application, reduce the cost of mechanization of the construction process, and therefore, the wage Fund. Manual installation involves the low weight of a single formwork element, which imposes requirements for the overall formwork scheme used in the product design material. A promising design should be modular each module that is made of either light concrete or plastic. A promising modular formwork must also have self-supporting capacity at the installation stage, which will allow the installation to abandon the supporting pillars [8]. The design of each formwork module in the form of a hollow block will solve the problem of the weight of each module and make it possible to fill the form of a fixed formwork with various heat and sound insulation materials to improve the corresponding characteristics (tab. 1).

Table 1. Comparison of characteristics.

\begin{tabular}{|c|c|c|c|c|c|c|c|}
\hline \multirow[b]{2}{*}{ Formwork type } & \multicolumn{7}{|c|}{ characteristic } \\
\hline & 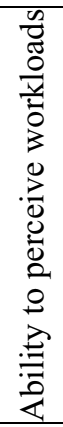 & 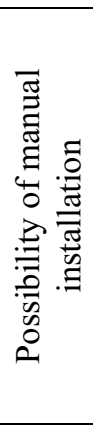 & 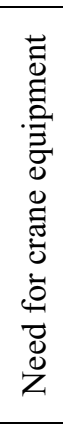 & 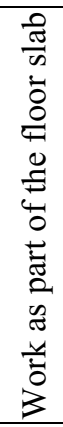 & 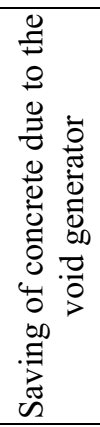 & 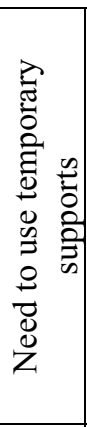 & 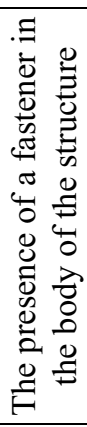 \\
\hline Hollow block slab & - & - & + & + & - & - & - \\
\hline Puzzle from & - & + & - & - & - & - & + \\
\hline Panel stay in place formwork & - & - & + & + & - & - & + \\
\hline $\begin{array}{l}\text { Block for blocking coastal } \\
\text { flow }\end{array}$ & - & - & + & - & - & + & + \\
\hline SIP formwork with blockout & - & - & + & + & + & - & - \\
\hline Promising formwork & + & + & - & + & - & - & + \\
\hline
\end{tabular}

Thus, a promising formwork system can be a set of inventory blocks made of light concrete, forming a monolithic floor by means of engagement. Each formwork block is a hollow parallelepiped with mixed bases on two adjacent sides of which there are trapezoidal wedges and grooves for them. 


\section{Conclusion}

Having considered the inventions in the field of fixed formwork, we can conclude that this research topic is relevant for modern construction. The ability to combine various technical solutions such as the modularity of the formwork system, the combination of the formwork block with the floor plate cavity, the use of energy-efficient materials and integrated engagement mechanisms made of the main material of the structure allow you to create a high-performance construction structure for solving most tasks in low-rise construction. The advantages of permanent formwork which is expressed in the cheapening and acceleration of the concrete work due to the lack of operations for the removed structures and a reduction in pour concrete to give additional preferences in the form of the ability to use less skilled labor for installation due to built-in product controllers without losing the quality of the finished design. However, along with the advantages described above, none of the inventions discussed above can completely get rid of some of the main features of classical floor formwork. The lack of self-supporting capacity in the structures at the installation stages involves the use of supporting racks, profile steel structures require an additional reinforcement frame and the supply of the mixture by concrete pumps or concrete bunkers. Hollow blocks and beams, due to their size, need lifting mechanisms and cannot be mounted manually. To solve these shortcomings, the further development path in the field of these technologies is outlined. Developed and proposed in the article, the technical description of the model of a promising fixed floor formwork will eliminate the listed shortcomings of existing systems and develop a springboard for further research in this direction.

\section{References}

1. Pavel Medvedev, Evgeniy Pugach, Pavel Gaidukov, Design Of Wooden Formwork For Brick Vaults; WMCOUS 2018-22 June, $3^{\text {rd }}$ World Multidisciplinary Civil Engineering-Arhitecture-Urban Planing Symposium, Prague 2018.

2. Zhejiang Gongshang Chu, Assembled coating of hollow block connected, China patent\$ CN2709558U.

3. Jean Levavasseur, Breese Majerowicz, SIMONNOT, France patent; FR2784124 04.07.2000.

4. A.G. Trushchev, S.V. Simkin and G.P. Ivanov, Panel stay in place formwork Rus patent Ru94022702A1.

5. Kim Kyu Han Block for blocking coastal flow, South Korea patent, KR101544039.

6. S.M. Anpilov, Monolithic floor slab for large spans, Rus patent Ru166521U1.

7. Hart Honickman, Noah Queen's University (Canada), Pultruded GFRP sections as stay-in-place structural open formwork for concrete slabs and girders; ProQuest Dissertations Publishing, 2008.ID250786277

8. X. Gai, A. Darby, T. Ibell, M. Evernden, Experimental investigation into a ductile FRP stay-in-place formwork system for concrete slabs; Construction and Building Materials. 2013. №49. pages. 1013-1023. 